\title{
The Impact of Workplace Stressors on Exhaustion and Work Engagement in Policing
}

\author{
Steven Lockey \\ University of Queensland ${ }^{1}$
}

Les Graham

Durham University ${ }^{2}$

Yuyan Zheng

Sheffield University ${ }^{3}$

Ian Hesketh*

College of Policing ${ }^{4}$

Marisa Plater

Durham University ${ }^{2}$

Sara Gracey

Durham University ${ }^{2}$

"Corresponding author: Ian Hesketh (email: ian.hesketh@college.pnn.police.uk)

\footnotetext{
${ }^{1}$ The University of Queensland Business School, The University of Queensland, Brisbane Qld 4072, Australia.

${ }^{2}$ Durham University Business School, Durham University, Durham, DH1 3LB, England, United Kingdom.

${ }^{3}$ Sheffield University Management School, The University of Sheffield, Conduit Road, Sheffield, S10 1FL, United Kingdom.

${ }^{4}$ College of Policing, 1-7 Old Queen Street, Westminster, London, SW1H 9HP, United Kingdom.
} 


\begin{abstract}
This paper uses the challenge-hindrance stressor framework to examine the impact of challenge and hindrance stressors on police officer and staff well-being. Results of two studies conducted in English police forces demonstrate that challenge stressors relate positively to the effort and enthusiasm individuals invest into their work. Findings also indicate that while challenge stressors are positively associated with exhaustion crosssectionally (Study 1, $N=469$ ), they do not impact exhaustion over time (Study 2, $N=823$ ). Conversely, hindrance stressors cause exhaustion in the long-term and are negatively associated with work engagement cross-sectionally. Implications for theory and practice are discussed.
\end{abstract}

Keywords: Challenge-hindrance, Stressors, Exhaustion, Work engagement, Policing. 


\section{Introduction}

Policing is a stressful, demanding, and frequently dangerous profession (Frank et al. 2017; Houdmont 2017; Martinussen et al. 2007). In the United Kingdom, the PEEL report by Her Majesty's Inspectorate of Constabulary and Fire and Rescue Services (HMICFRS 2017, 7) notes that despite generally coping well with the varied and increasing demands they face under an unprecedented period of reform, police forces in England and Wales remain under 'significant stress'. Further, the HMICFRS 2017 Leadership report stresses the importance of well-being of the workforce, observing that 'forces need to address the levels of stress and heavy workloads of officers and staff protecting vulnerable people' (HMICFRS 2018, 33). The Demand, Capacity, and Welfare Survey undertaken by the Police Federation of England and Wales (PFEW) report (ElliottDavies 2018) notes that almost $80 \%$ of police officer respondents acknowledged experiencing stress, low mood, anxiety, or other mental health or well-being difficulties within the previous 12 months. $94 \%$ of this sub-sample indicated that their psychological well-being issues were caused or made worse by work (Elliott-Davies 2018). As Hesketh and Cooper $(2018,4)$ note: 'stress cannot be separated from wellbeing, and neither should it'.

Organisational stressors can be defined as characteristics of an organisation and conditions in the workplace that can cause employees to experience stress (Violanti and Aron 1995). Prior research in policing has consistently supported the hypothesis that organisational stressors have negative impacts on police officers and staff (Biggam et al. 1997; Gershon et al. 2009; Houdmont 2017; Shane 2010; Zhou et al. 2002). However, seminal work in the stress literature has suggested that there can be both positive and negative forms of stress (Lazarus and Folkman 1984; Selye 1974). Furthermore, the well-established challenge-hindrance stressor framework (Cavanaugh et al. 2000) proposes that good stressors, or challenge stressors, which refer to perceptions of work- 
related demands such as workload, time pressure, responsibility and job complexity, will increase stress, but also hold the potential for increasing work motivation and performance. On the other hand, bad stressors, or hindrance stressors, which refer to perceptions of work-related demands such as red tape, role ambiguity, administrative hassles, and office politics, act as barriers to achievement and have harmful effects on employees' wellbeing. Prior research in non-police contexts has provided support for the challenge-hindrance stressor framework in predicting differential impacts of organisational stressors on job attitudes (Cavanaugh et al. 2000; Podsakoff et al. 2007), performance (LePine et al. 2005; Zhang et al. 2014), and well-being (Crane and Searle 2016; LePine et al. 2005; Van den Broeck et al. 2009).

In this paper, we provide a first test of the challenge-hindrance stressor framework (Cavanaugh et al. 2000) in a policing context to develop a more nuanced understanding of the impact of organisational stressors on individual well-being in policing. Specifically, we examine the impact of challenge and hindrance stressors on exhaustion and work engagement. Exhaustion is a consequence of intensive physical, affective and cognitive strain, that is, as a long-term consequence of certain job demands (Demerouti et al. 2003), and is central to the experience of burnout (Maslach and Jackson 1981). In turn, burnout is associated with several undesirable personal and organisational outcomes, such as physical and psychological problems, job dissatisfaction and absenteeism (for a recent review, see Salvagioni et al. [2017]). Conversely, work engagement is commonly defined as: 'a positive, fulfilling work-related state of mind that is characterised by vigour, dedication and absorption' (Schaufeli et al. 2002, 74). Work engagement has been found to be associated with employee well-being and performance (e.g. Christian et al. 2011; Halbesleben 2010). 
Drawing on Conservation of Resources theory (COR: Hobfoll 1989), we posit that hindrance stressors will be associated with reduced employee well-being, in that it is positively related to exhaustion and negatively related to employee engagement. While we expect that challenge stressors are also positively related to exhaustion, we investigate whether the impact is lower than that of hindrance stressors. We also theorise and test that challenge stressors can be considered as good stressors in contrast to hindrance stressors in that they act to increase motivation and will be positively related to employee engagement. Our hypothesised model is displayed in Figure 1.

Insert Figure 1 about here

While Study 1 is cross-sectional in Study 2 data were collected in two waves; with the dependent variables of engagement and exhaustion measured 24 months after the independent variables of challenge and hindrance stressors. This is important, as most studies of the challengehindrance stressor framework utilise cross-sectional designs (Crawford et al. 2010; French et al. 2019; Yao et al. 2015). By temporally separating challenge and hindrance stressors from important individual and organisational outcomes, we meet the calls of Yao and colleagues (2015) and LePine et al. (2005) for investigation of the causal influence of the challenge-hindrance stressor framework. 


\section{Theory Development and Hypothesis Formation}

\section{The Challenge-Hindrance Stressor Framework and Conservation of Resources (COR) Theory}

Conservation of Resources (COR) theory (Hobfoll 1989) posits that individuals strive to develop, maintain, and protect resources. Resources are defined 'as those objects, personal characteristics, conditions, or energies that are valued by the individual or that serve as a means for attainment of those objects, personal characteristics, conditions or energies' (Hobfoll 1989, 516). According to COR theory, stress occurs under three conditions. First, when individuals' key resources are threatened with loss. Second, when resources are lost. Third, when individuals fail to gain resources after significant resource investment. Stress experienced under these conditions leads to individuals becoming depleted and experiencing burnout over time (Hobfoll and Freedy 1993) and individuals are only likely to invest their resources (such as effort, time, and energy) into meeting demands that offer the potential for resource gains (Dawson et al. 2016).

\section{The Impact of Challenge and Hindrance Stressors on Exhaustion}

The stressors-strain approach to work-related stress provides an explanation as to why stressors lead to exhaustion. Exhaustion occurs as a consequence of prolonged intensive physical, affective and cognitive strain experienced as a result of long-term exposure to high job demands (Demerouti et al. 2010). Moreover, the information processing activity undertaken as individuals try to cope with and make sense of the demands they face in their work this can have further heavy emotional and physiological costs (Hockey 1997). Increased levels of arousal occur whether stressors are is appraised as being positive or negative (Lazarus and Folkman 1984). As such, both challenge and hindrances stressors are likely to result in exhaustion over time. This proposition is supported by previous research, which has found positive relations between exhaustion and both 
forms of stressor investigated in the present study. Two meta-analyses reported such effects (Crawford et al. 2010; LePine et al. 2004), while Yao and colleagues (2015) found the expected relationships across two studies. However, both meta-analyses note that the studies they investigate used cross-sectional designs, as did Yao et al. (2015). As such, by undertaking a longitudinal design in Study 2 to examine causality, we make an important contribution to literature.

Hypothesis 1: Challenge stressors are positively related to exhaustion.

Hypothesis 2: Hindrance stressors are positively related to exhaustion.

\section{The Impact of Challenge and Hindrance Stressors on Work Engagement}

Work engagement refers to the extent to which employees perceive their work to be meaningful, stimulating and engrossing (Bakker et al. 2011; Rich et al. 2010). Drawing on COR theory, we expect challenge stressors to motivate individuals to gain more resources, as meeting challenging but rewarding demands can instil a sense of achievement and lead to other resource gains relating to well-being (Widmer et al. 2012), goal attainment, and personal development (LePine et al. 2004). Therefore, challenge stressors should be engaging. Conversely, because they act as barriers to achievement and personal development, hindrance stressors are likely to be considered as resource threats. Faced with such workplace barriers, employees are likely to conserve their existing resources by reserving their energies and engaging less with their work.

Our theorising is supported by previous research that demonstrates the differential influence of challenge and hindrance stressors on work engagement; that challenge stressors impact positively and hindrance stressors impact negatively on work engagement (Crawford et al. 2010; Tadić et al. 2015). Based on these findings, we posit: 
Hypothesis 3: Challenge stressors are positively related to work engagement.

Hypothesis 4: Hindrance stressors are negatively related to work engagement.

\section{Method}

\section{Overview of the research}

We used two samples (Study 1 and 2) from different English police forces to test our hypotheses. Study 1 used a cross-sectional sample of 469 police officers and police staff. In Study 2, 823 participants completed a two-wave survey, such that both predictors and outcomes were assessed at Time 1 (baseline), and outcome measures were assessed again 24 months later (Time 2). Using cross-lagged dependent variables was helpful in reducing concerns of assumed direction of causality (Podsakoff, MacKenzie, Lee, \& Podsakoff, 2003).

\section{Study 1}

\section{Sample and procedures}

Participants completed surveys assessing the frequency they experienced challenge and hindrance stressors. Further, we also asked the participants to rate their levels of exhaustion and work engagement. The sample comprised of 469 employees from an English police force (60.8\% male and $39.2 \%$ female). In terms of job roles, $62.5 \%$ were police officers, and $38.5 \%$ were police staff. Two percent of them were between 18-24 years old, 19\% of them were between 2534 years old, $33 \%$ of them were between 35-44 years old, 35\% of them were between 45-54 years old and $11 \%$ were 55 years and above. Three per cent had worked in policing for less than 1 year, $12 \%$ had worked $1-5$ years, $18 \%$ had worked 6-10 years, $39 \%$ had worked $11-20$ years, and $28 \%$ of had worked in policing for more than 20 years. 


\section{Measures}

Stressors. We used six items from Cavanaugh et al. (2000) to measure challenge stressors, and seven items from the same scale to measure hindrance stressors. For challenge stressors, sample items included: "having to complete a lot of work", "having to work very hard" and "having to perform complex tasks" $(\alpha=.89)$. For hindrance stressors, sample items included: "bureaucratic constraints to completing work (red tape)", "administrative hassles" and "unclear job tasks" $(\alpha=.85)$. Participants were asked to rate the frequency of experiencing these factors in their daily work, from $1=$ never to $5=$ extremely often.

Exhaustion. Exhaustion was measured using the eight-item subscale of the Oldenburg Burnout Inventory developed by Demerouti et al. (2003). Items were rated on a scale from $1=$ strongly disagree to $7=$ strongly agree. Sample items included: 'during work, I often feel emotionally drained' and 'after my work I usually feel worn out and weary' $(\alpha=.86)$.

Work Engagement. We measured engagement with nine items from Rich and colleagues' (2010) job engagement scale. Items were rated on a scale from $1=$ strongly disagree to $7=$ strongly agree. Sample items include: 'At work I focus a great deal of attention on my job' and 'I exert my full effort to my job' $(\alpha=.92)$.

Control Variables. Prior research shows that demographic variables influence individuals' work attitudes (e.g., Brouwer et al. 2010). We considered gender $(0=$ male, $1=$ female $)$, age $(0=$ 16-24 years, $1=25-34$ years, $2=35-44$ years, $3=45-54$ years, and $4=55$ years above), job roles $(0=$ police officers, $1=$ police staff $)$, and tenure in policing $(0=$ less than 1 year, $1=1-5$ years, 2 $=6-10$ years, $3=11-20$ years, and $4=20$ years and above) as control variables in our analyses. 


\section{Results}

\section{Preliminary results}

Table 1 shows the descriptive statistics and correlations among variables in Study 1. We found that challenge stressors had a positive correlation with exhaustion $(r=.40, p<.01)$, but were not significantly correlated with work engagement $(r=.09, p=n . s$.$) . As expected, hindrance$ stressors were positively correlated with exhaustion $(r=.58, p<.01)$, and were negatively correlated with work engagement $(r=-.28, p<.01)$.

Insert Table 1 about here

\section{Hypothesis testing}

We conducted hierarchical regression analyses in SPSS to test our hypotheses. As shown in Table 2, we first entered demographics as control variables in Model 1a, and then entered challenge stressors and hindrance stressors in Model 2a. Model 2a demonstrates that both challenge stressors and hindrance stressors were positively related to exhaustion $(B=.20, p<.01$ and $B=.67, p<.001$, respectively). These results supported Hypothesis 1 and Hypothesis 2. Examination of the standardised coefficients revealed that the hindrance stressors had a stronger positive relationship between exhaustion than challenge stressors $(\beta=.47, p<.001$ and $\beta=.13$, $p<.01$, respectively). In addition, Model $2 \mathrm{~b}$ showed that challenge stressors were positively related to work engagement $(B=.52, p<.001)$, while hindrance stressors were negatively related to work engagement $(B=-.51, p<.001)$, supporting Hypothesis 3 and Hypothesis 4 . 
Insert Table 2 about here

\section{Study 2}

Study 1 provided initial support for the hypotheses by using cross-sectional data. Study 2 extended Study 1 by using cross-lagged data to address common-method variance concerns. Data were collected from two English police forces different to that in Study 1. First, at Time 1, respondents were asked the rate their experience of challenge stressors and hindrance stressors, as well as their exhaustion and work engagement. Twenty-four months later, at Time 2, respondents were asked to rate their levels of exhaustion and work engagement. To match responses from the two time points, each questionnaire was coded with an assigned identification number. This approach allowed us to conduct autoregression between Time 1 outcomes and Time 2 outcomes, and examine how they change over time.

The matched sample consisted of 823 employees. Of these participants, $458(55.7 \%)$ were male and $365(44.3 \%)$ were female; 411 were police officers $(49.9 \%)$ and $412(50.1 \%)$ were police staff.

\section{Measures}

We used the same scales to assess the challenge and hindrance stressors and exhaustion as those used in Study 1 ( $\alpha=.87$ for challenge stressors; $\alpha=.84$ for hindrance stressors; $\alpha=.87$ for Time 1 exhaustion; $\alpha=.86$ for Time 2 exhaustion). To measure work engagement, we used six items selected from the original measure. The items were: 'I am enthusiastic in my job', 'I feel energetic at my job', 'At work my mind is focused on my job', 'At work I focus a great deal 
of attention on my job', 'I exert my full effort to my job', and 'I devote a lot of energy to my job' $(\alpha=.87$ for Time 1 and $\alpha=.89$ for Time 2$)$.

Control Variables. We controlled gender $(0=$ male, $1=$ female $)$ and job role $(0=$ police officers, 1 = police staff) in our analyses.

\section{Results}

\section{Preliminary results}

Table 3 shows the descriptive statistics and correlations among variables in Study 2 . Challenge stressors had a positive correlation with exhaustion measured at both Time 1 ( $r=.35$, $p<.01)$ and Time $2(r=.28, p<.01)$, and with work engagement at both Time $1(r=.10, p<.01)$ and Time $2(r=.13, p<.01)$. Hindrance stressors were positively correlated with exhaustion at Time $1(r=.50, p<.01)$ and Time $2(r=.39, p<.01)$, and were negatively correlated with work engagement at Time $1(r=-.26, p<.01)$ and Time $2(r=-.13, p<.01)$.

Insert Table 3 about here

\section{Hypothesis testing}

As in Study 1, we conducted hierarchical regression analyses to test our hypotheses. We included auto-regressions among exhaustion and work engagement measured at each of the two time points.

Table 4 shows that after controlling for baseline exhaustion, challenge stressors were not related to exhaustion at Time 2 (Model 2a: $B=.05$, n.s.) while hindrance stressors significantly increased exhaustion over time $(B=.10, p<.05)$. Thus, Hypothesis 2 was supported, but 
Hypothesis 1 was not. In addition, after controlling for baseline work engagement, challenge stressors were positively related to work engagement at Time $2(B=.10, p<.05)$ while hindrance stressors did not have a significant impact on work engagement over time $(B=-.01, n . s$.$) . These$ results supported Hypothesis 3, but not Hypothesis 4.

Insert Table 4 about here

\section{Discussion}

Police forces in England and Wales face increasingly complex challenges under budget restraints (HMIC 2017a, HMICFRS 2017b). These challenges have resulted in reduced staff levels, and consequently officers and staff have reported high levels of stress (Elliot-Davies 2018). The primary aim of this study was to apply the challenge-hindrance stressor framework (Cavanaugh et al. 2000) to the new context of policing based on its successful application in a variety of other contexts (see for example, Cavanaugh et al., 2000; Crane and Searle, 2016; Wallace et al. 2009). The reasoning for this was that grouping organisational stressors into a single dimension may inadvertently mask the true relationships between stress and well-being outcomes. For example, workload has been considered as an organisational stressor in prior policing research (i.e. Violanti and Aron 1995) and organisational factors tend to be perceived as more stressful than operational stressors in the police context (Houdmont 2017). However, the challenge-hindrance stressor framework proposes that simply having a high workload, in itself, may not be the main impact on an individuals' well-being, and that organisational stressors do not necessarily lead to negative outcomes. Our findings broadly support the conclusions of previous research conducted in non- 
policing contexts into the effects of challenge and hindrance stressors on well-being outcomes (i.e. Crawford et al. 2010; LePine et al. 2005; Van den Broeck et al. 2010; Yao et al. 2015). They do so both cross-sectionally and longitudinally, addressing calls in the literature to demonstrate the causal impact of the challenge-hindrance stressor framework (Crawford et al. 2010; LePine et al. 2005; Yao et al. 2015). Specifically, and drawing on Conservation of Resources theory (Hobfoll 1989), we found that challenge stressors positively influenced work engagement both crosssectionally and over time, and hindrance stressors were positively related to exhaustion crosssectionally and over time. Further, while challenge stressors were found to have a positive association with exhaustion when measured at the same time, there was no significant relationship when exhaustion was measured 24 months later. Previous cross-sectional work tends to find positive associations between challenge stressors and exhaustion, as we did in Study 1. However, the longitudinal findings of Study 2 provide some preliminary evidence that challenge stressors may not be a primary cause of exhaustion over a longer period of time. We discuss the practical implications of this point in the following section. Hindrance stressors had a negative relationship with work engagement when measured at the same time, but there was no significant relationship with work engagement measured 24 months later. These results indicate the negative impact of hindrance stressors and the potential benefits challenge stressors can hold over time. More broadly, they indicate that the challenge-hindrance stressor framework is applicable in policing and provide a more nuanced understanding of the complex relationship between organisational stressors and employee well-being.

\section{Practical Implications}

The findings of our study have several practical implications for police forces. First, and supported consistently by extant research, our results indicate that hindrance stressors have 
negative effects on well-being. Indeed, our findings add to the developing body of literature on the negative impact of hindrance stressors (i.e. Cavanaugh et al. 2000; Crane and Searle 2016; LePine et al. 2005, 2016; Podsakoff et al. 2007). To our knowledge, no existing studies on the subject have found any "positive" outcomes of hindrance stressors. As such, they should be reduced or removed where possible. Although hindrances such as red tape, politics, and administrative hassles are simply part of the fabric of organisational life, they can be improved upon over time. Further, while making major systemic changes to an organisational framework may be too costly or otherwise not immediately viable, making small, incremental changes to practices, processes, and procedures can make a big difference. As an example from the Participatory Action Research approach undertaken through the Durham University research collaboration project (see Hesketh and Graham 2017), several forces have shared their practices relating to 100 Little Things initiatives. Pioneered by Durham Constabulary, 100 Little Things is a project that encourages staff to submit suggestions for workplace improvements ranging from the type of pen issued to officers, to new policies, procedures, and working patterns. HMICFRS (2017a) gave Durham Constabulary an "outstanding" rating. An aspect of this pertains to how the force understands demand, and HMICFRS (2017a) specifically commended Durham for the inclusive way it turns to its workforce for idea generation, citing the 100 Little Things project as a success and an example of an outstanding approach to seeking new ideas. The initiative is a mechanism through which employees are given voice and can provide ideas to make their workplace better and their jobs easier. In other words, at its heart, a major purpose of 100 Little Things is to remove hindrances faced by police officers and staff.

While recommendations relating to reducing hindrance stressors are clear, the impact of increasing challenge stressors should be carefully considered. In line with previous research, our 
findings indicate that challenge stressors can lead to greater work engagement (Crawford et al. 2010; Tadić et al. 2015). Further, prior research has demonstrated other positive effects of challenge stressors, including positive associations with performance (LePine et al. 2005, 2016; Zhang et al. 2014) and positive job-related attitudes (Cavanaugh et al. 2000; Podsakoff et al. 2007), suggesting that challenge stressors can be beneficial. However, prior work has found challenge stressors to be positively related to exhaustion (LePine et al., 2004, 2005; Podsakoff et al. 2007; Zhang et al. 2014). While our results did not replicate these findings over a time period of two years, cross-sectional results were supportive of the expected relationship found in previous work. As such, we believe it is important for forces to consider how to reduce the strain associated with increased challenge stress. There are several ways to do this. One is to provide organisational support by valuing the contributions of staff, caring about their well-being, and fulfilling their socioemotional needs (Eisenberger et al. 1986). Indeed, in a US sample of public sector workers, Wallace et al. (2009) found that challenge stressors were positively related to in-role performance when organisational support was high, but not when it was low. This suggests that organisations need to be supportive for employees to benefit from challenge stressors. Supervisors are tangible representatives of an organisation, and as such, supportive treatment from one's supervisor should contribute to an employee's overall perceptions of organisational support (Rhoades and Eisenberger 2002) and be considered a valued resource (Hobfoll 1989). In support of this proposal, LePine et al. (2016) found that US marines whose leaders were perceived by their superiors to exhibit charismatic leadership behaviours appraised challenge stressors as being more challenging. In turn, the marines were more likely to respond with greater performance. Further, while charismatic leader behaviours negated the negative influence of hindrance stressors on performance. The results of these studies suggest that forces should consider training supervisors 
on the importance of being supportive of employees. Prior research suggests that police officers and staff in England and Wales perceive a general shift from the traditional command and control, authoritarian style of leadership to more open, inclusive leadership in policing (Porter et al. 2015). We encourage forces to continue on this path in order to support staff in benefiting from challenge stressors, in line with the College of Policing's $(2015,2017)$ recommendations on promoting and developing effective organisational leadership principles and practices. Forces can also provide tangible resources to officers and staff to support them in reducing the strain associated with challenge stressors. This proposition is based on one of the corollaries of Conservation of Resources theory (Hobfoll 1989), that when people possess strong resource pools, they are more likely to accept or seek out opportunities to risk resources in order to obtain further resource gains. A practical example would be providing training programmes on subjects such as resilience. Robertson et al. (2015, 27, emphasis added) note that organisational and personal resilience are imperative 'not only to enhance productivity, but also to foster well-being and engagement'. Hesketh et al. (2019) studied the effects of resilience training on staff and officers in a provincial police force in the north of England. They found that those who received resilience training reported that their workload, work-life balance, job control, and job conditions had improved compared to those who had not received training, indicating the training's efficacy in improving several aspects of well-being in policing. Providing resilience training while increasing challenge stressors may have a multiplicative effect, as Crane and Searle (2016) found that challenge stressors measured at Time 1 were positively associated with resilience measured at Time 2 (three months later). Further, resilience at Time 1 was negatively related to strain at Time 2, indicating the positive influence resilience can have in reducing strain. The implications of these findings are 
that implementing resilience training to support employees in coping with challenge stressors can have positive, reinforcing effects.

\section{Limitations and Directions for Future Research}

A strength of the current study is that we were able to broadly replicate Study 1's crosssectional findings across time in Study 2. In Study 2, we measured the well-being indicators of exhaustion and work engagement two years after collecting data pertaining to challenge and hindrance stressors, reducing the potential impact of common method variance (CMV). CMV refers to the variance attributable to the measurement method undertaken rather than the constructs the measures represent (Podsakoff et al. 2003). However, there may be common source effects, which can occur when the respondent providing the measure of the independent variable (i.e. the stressors) and the dependent variable (i.e. the well-being indicators) is the same person (Podsakoff et al. 2003). By temporally separating the measurement of the independent and dependent variables, we have taken steps to guard against this, but future studies could build on our findings by obtaining data from multiple sources. For example, asking supervisors or co-workers to rate the respondent's work engagement, and asking a spouse, partner, or close family member to rate their personal well-being (i.e. exhaustion or life satisfaction).

In addition, generalisability of our results cannot be assumed as both of our studies sampled employees of English police forces. While our findings broadly support those reported using samples from a range of professions, the majority of those studies were cross-sectional. As such, we would encourage future research to attempt to replicate our longitudinal results in different contexts. Furthermore, Roach et al. (2017) observe that individuals in different occupational roles within policing may be exposed to different levels and forms of stress due to the specific nature of their work. This observation is supported by the findings in a national study of the wellbeing of the policing workforce 
within England and Wales (Graham et al. 2020) in that average wellbeing was found to vary for different occupational job role for police officers and police staff. Due to the sample and data collection in this study we were unable to investigate how challenge and hinderance stressors are experienced in different occupational roles and would encourage further research to investigate these differences too provide insight and understanding which would be of great value in terms of prioritising corrective action. We also recognise the limitations of the findings in terms of the survey research methodology adopted and suggest that these findings could be built-upon using interviews or focus groups with police officers and staff in specific occupational roles to understand their lived experiences of dealing with different stressors in their work.

Finally, while this study provides further evidence of the efficacy of the hindrance-stressor framework and is the first to do so in a policing context, more research, particularly into challenge stressors, is warranted. Specifically, future research may consider how the impact of training programmes, such as those discussed in the previous section, may influence the effects of challenge and hindrance stressors on well-being outcomes. For instance, employees who undergo resilience training may not feel as exhausted by either type of stressor than those who do not. Further, those who are better able to recover and "recharge" while not at work may experience greater benefits of experiencing challenge stressors due to reducing associated strain. Research into how recovery in non-work time (i.e. Sonnentag et al. 2011) influences the effects of challenge stressors on exhaustion would be useful.

\section{Conclusion}

The findings of this study provide evidence that the challenge-hindrance stressor framework is a useful way to understand the nuanced relationship between stressors and wellbeing outcomes in policing. They indicate that hindrance stressors are associated with increased 
exhaustion in police officers and staff. As such, forces should aim to eliminate or reduce hindrance stressors where possible. Conversely, challenge stressors are associated with increased engagement. However, challenge stressors were also associated with exhaustion in our crosssectional study, even if there was no significant relationship between the two variables when exhaustion was measured 24 months later. Notwithstanding, when increasing challenge stressors, forces should be mindful to mitigate any associated strain to guard against burnout and provide the best opportunity for staff to benefit from them. 


\section{References}

Bakker AB, Albrecht SL and Leiter MP (2011) Key questions regarding work engagement. European Journal of Work and Organizational Psychology, 20(1), pp.4-28. doi: 10.1080/1359432X.2010.485352.

Biggam FH, Power KG, Macdonald R, Carcary WB and Moodie, E (1997) Self-perceived occupational stress and distress in a Scottish police force. Work Stress: An International Journal of Work, Health \& Organisations 11(2): 118-133. doi: 10.1080/02678379708256829.

Brouwer S, Reneman MF, Bültmann U, Van der Klink JJ and Groothoff JW (2010) A prospective study of return to work across health conditions: perceived work attitude, selfefficacy and perceived social support. Journal of Occupational Rehabilitation, 20(1), pp.104112.doi: 10.1007/s10926-009-9214-Z.

Cavanaugh MA, Boswell WR, Roehling MV and Boudreau JW (2000) An empirical examination of self-reported work stress among US managers. Journal of Applied Psychology, 85(1), pp.65-74. doi: 10.1037/0021-9010.85.1.65.

Christian MS, Garza AS and Slaughter JE (2011) Work engagement: A quantitative review and test of its relations with task and contextual performance. Personnel Psychology, 64(1), pp.89-136. doi: 10.1111/j.1744-6570.2010.01203.x.

College of Policing (2015) Leadership Review: Recommendations for delivering leadership at all levels. Coventry: College of Policing.

College of Policing (2017) Guiding principles for organisational leadership. Coventry: College of Policing.

Crane MF and Searle BJ (2016) Building resilience through exposure to stressors: The effects of challenges versus hindrances. Journal of Occupational Health Psychology, 21(4), pp.468-479. doi: $10.1037 / \mathrm{a} 0040064$.

Crawford ER, LePine JA and Rich BL (2010) Linking job demands and resources to employee engagement and burnout: a theoretical extension and meta-analytic test. Journal of Applied Psychology, 95(5), pp.834-848. doi: 10.1037/a0019364. 
Davey JD, Obst PL and Sheehan MC (2001) Demographic and workplace characteristics which add to the prediction of stress and job satisfaction within the police workplace. Journal of Police and Criminal Psychology, 16(1), pp.29-39. doi: 10.1007/BF02802731.

Dawson KM, O'Brien KE. and Beehr TA (2016) The role of hindrance stressors in the job demand-control-support model of occupational stress: A proposed theory revision. Journal of Organizational Behavior, 37(3), pp.397-415. doi: 10.1002/job.2049.

Demerouti E, Bakker AB, Vardakou I. and Kantas A (2003) The convergent validity of two burnout instruments: A multitrait-multimethod analysis. European Journal of Psychological Assessment, 19(1), pp.12-23. doi: 10.1027//1015-5759.19.1.12.

Demerouti E, Mostert K and Bakker AB (2010) Burnout and work engagement: a thorough investigation of the independency of both constructs. Journal of Occupational Health Psychology, 15(3), pp.209-222. doi: 10.1037/a0019408.

Eisenberger R, Huntington R, Hutchison S and Sowa, D (1986) Perceived organizational support. Journal of Applied Psychology, 71(3), pp.500-507. doi: 10.1037/0021-9010.71.3.500.

Elliott-Davies M (2018) PFEW 2018 Demand, Capacity, and Welfare Survey 2018: Headline Statistics. Surrey: The Police Federation of England and Wales.

Frank J, Lambert EG and Qureshi H (2017) Examining police officer work stress using the job demands-resources model. Journal of Contemporary Criminal Justice, 33(4), pp.348-367. doi: $10.1177 / 1043986217724248$.

French KA, Allen TD and Henderson TG (2019) Challenge and hindrance stressors and metabolic risk factors. Journal of Occupational Health Psychology, 24(3), pp.307-321. doi: 10.1037/ocp0000138.

Gershon RR, Barocas B, Canton AN, Li X and Vlahov D (2009) Mental, physical, and behavioral outcomes associated with perceived work stress in police officers. Criminal Justice and Behavior, 36(3), pp.275-289. doi: 10.1177/0093854808330015.

Graham L, Brown N, Plater M, Gracey S, Legate N, and Weinstein N. (2020) National Policing Wellbeing Survey 2019: Summary of Evidence and Insights. Durham University, March 2020. Available at https://oscarkilo.org.uk/app/uploads/2020/06/ISSUED-2019-National-PoliceWellbeing-Survey-1.pdf. 
Halbesleben JB. (2010) A meta-analysis of work engagement: Relationships with burnout, demands, resources, and consequences. In: Bakker AB and Leiter MP (eds) Work Engagement: A Handbook of Essential Theory and Research. Hove UK: Psychology Press, pp. 102-117

Hesketh I and Graham L (2017) Theory or not theory? That is the question. Australasian Policing: A Journal of Professional Practice and Research., 9(1), pp.10-12. ISSN: 1837-7009.

Hesketh I, Cooper CL and Ivy J (2017) Wellbeing and engagement in policing: the key to unlocking discretionary effort? Policing: A Journal of Policy and Practice, 11(1), pp.62-73. doi: 10.1093/police/paw021.

Hesketh I, Cooper CL and Ivy J (2019) Leading the asset: Resilience training efficacy in UK policing. The Police Journal, 92(1), pp.56-71. doi: 10.1177/0032258X18763101.

HMIC (2017) State of Policing: The Annual Assessment of Policing in England and Wales 2016. London: Her Majesty's Inspectorate of Constabulary.

HMICFRS (2017a) Durham PEEL 2017 - Efficiency. Available from https://www.justiceinspectorates.gov.uk/hmicfrs/peel-assessments/peel2017/durham/efficiency/

HMICFRS (2017b) PEEL - Police Efficiency 2017: A National Overview. London: Her Majesty's Inspectorate of Constabulary and Fire \& Rescue Services.

HMICFRS (2018) PEEL - Police Leadership 2017: A National Overview. London: Her Majesty’s Inspectorate of Constabulary and Fire \& Rescue Services.

Hobfoll SE (1989) Conservation of resources: A new attempt at conceptualizing stress. American Psychologist, 44(3), pp.513-524. doi: 10.1037//0003-066x.44.3.513.

Hobfoll SE and Freedy J (1993) Conservation of resources: A general stress theory applied to burnout. In: Schaufeli, WB, Maslach, C, \& Marek T (eds.) Professional burnout: Recent developments in theory and research. Philadelphia, PA: Taylor \& Francis, pp. 115-133.

Hockey GRJ (1997) Compensatory control in the regulation of human performance under stress and high workload: A cognitive-energetical framework. Biological Psychology,45(1-3), pp.7393. doi: 10.1016/s0301-0511(96)05223-4. 
Houdmont J (2017) Stressors in police work and their consequences, In: Burke RJ (ed) Stress in Policing: Sources, consequences and interventions. London: Routledge, pp. 51-65. Lazarus R and Folkman S (1984). Stress, Appraisal, and Coping. New York: Springer.

LePine JA, LePine MA and Jackson CL (2004) Challenge and hindrance stress: relationships with exhaustion, motivation to learn, and learning performance. Journal of Applied Psychology, 89(5), pp.883-891. doi: 10.1037/0021-9010.89.5.883.

LePine JA, Podsakoff NP and LePine MA (2005) A meta-analytic test of the challenge stressorhindrance stressor framework: An explanation for inconsistent relationships among stressors and performance. Academy of Management Journal, 48(5), pp.764-775.doi: $10.2307 / 20159696$.

LePine MA, Zhang Y, Crawford ER and Rich BL. (2016) Turning their pain to gain: Charismatic leader influence on follower stress appraisal and job performance. Academy of Management Journal, 59(3), pp.1036-1059. doi: 10.5465/amj.2013.0778.

Martinussen M, Richardsen AM and Burke RJ (2007) Job demands, job resources, and burnout among police officers. Journal of Criminal Justice, 35(3), pp.239-249. doi: 10.1016/j.jcrimjus.2007.03.001.

Maslach C and Jackson SE (1981) The measurement of experienced burnout. Journal of Organizational Behavior, 2(2), pp.99-113. doi: 10.1002/job.4030020205.

Podsakoff NP, LePine JA and LePine MA (2007). Differential challenge stressor-hindrance stressor relationships with job attitudes, turnover intentions, turnover, and withdrawal behavior: a meta-analysis. Journal of Applied Psychology, 92(2), pp.438-454. doi: 10.1037/0021-9010.92.2.438.

Podsakoff PM, MacKenzie SB, Lee JY and Podsakoff NP (2003) Common method biases in behavioral research: a critical review of the literature and recommended remedies. Journal of Applied Psychology, 88(5), pp.879-903. doi: 10.1037/0021-9010.88.5.879.

Porter L, Webb S, Prenzler T and Gill M (2015). The role of leadership in promoting ethical police behaviour. College of Policing, Coventry. 
Rhoades L and Eisenberger R (2002) Perceived organizational support: a review of the literature. Journal of Applied Psychology, 87(4), pp.698-714. doi: 10.1037/0021-9010.87.4.698.

Roach J, Cartwright A and Sharratt K (2017) Dealing with the Unthinkable: a Study of the Cognitive and Emotional Stress of Adult and Child Homicide Investigations on Police Investigators. Journal of Police and Criminal Psychology, 32(3), 251-262. doi: 10.1007/s11896-016-9218-5.

Robertson IT, Cooper CL, Sarkar M and Curran T (2015) Resilience training in the workplace from 2003 to 2014: A systematic review. Journal of Occupational and Organizational Psychology, 88(3), pp.533-562. doi: 10.1111/joop.12120.

Rich BL, Lepine JA and Crawford ER (2010) Job engagement: Antecedents and effects on job performance. Academy of Management Journal, 53(3), pp.617-635. doi: 10.5465/amj.2010.51468988.

Salvagioni DAJ, Melanda FN, Mesas AE, González AD, Gabani, FL and de Andrade SM (2017) Physical, psychological and occupational consequences of job burnout: A systematic review of prospective studies. PloS one. doi: 10.1371/journal.pone.0185781.

Schaufeli WB, Salanova M, González-Romá V and Bakker AB (2002) The measurement of engagement and burnout: A two sample confirmatory factor analytic approach. Journal of Happiness Studies, 3(1), pp.71-92. doi: 10.1023/A:1015630930326.

Selye, H (1974) Confusion and Controversy in the Stress Field. Journal of Human Stress 1(2), pp.37-44. doi: 10.1080/0097840X.1975.9940406.

Shane JM (2010) Organizational stressors and police performance. Journal of Criminal Justice 38(4), pp.807-818. doi: 10.1016/j.jcrimjus.2010.05.008.

Sonnentag S, Kuttler I and Fritz C (2010) Job stressors, emotional exhaustion, and need for recovery: A multi-source study on the benefits of psychological detachment. Journal of Vocational Behavior, 76(3), pp.355-365. doi: 10.1016/j.jvb.2009.06.005. 
Tadić M, Bakker AB and Oerlemans W.G (2015) Challenge versus hindrance job demands and well-being: A diary study on the moderating role of job resources. Journal of Occupational and Organizational Psychology, 88(4), pp.702-725. doi: 10.1111/joop.12094.

Van den Broeck A, De Cuyper N, De Witte H and Vansteenkiste M (2010) Not all job demands are equal: Differentiating job hindrances and job challenges in the Job Demands-Resources model. European Journal of Work and Organizational Psychology, 19(6), pp.735-759. doi: $10.1080 / 13594320903223839$.

Violanti JM and Aron F (1995) Police stressors: Variations in perception among police personnel. Journal of Criminal Justice, 23(3), pp.287-294. doi: 10.1016/00472352(95)00012-F.

Wallace JC., Edwards BD, Arnold T, Frazier ML and Finch DM (2009) Work stressors, rolebased performance, and the moderating influence of organizational support. Journal of Applied Psychology, 94(1), pp.254-262. doi: 10.1037/a0013090.

Widmer PS, Semmer NK, Kälin W, Jacobshagen N and Meier LL (2012) The ambivalence of challenge stressors: Time pressure associated with both negative and positive well-being. Journal of Vocational Behavior, 80(2), pp.422-433. doi: 10.1016/j.jvb.2011.09.006.

Yao AY, Jamal M and Demerouti E (2015) Relationship of challenge and hindrance stressors with burnout and its three dimensions. Journal of Personnel Psychology, 14, pp. 203-212. doi: 10.1027/1866-5888/a000141.

Zhang Y, Le Pine JA, Buckman BR and Wei F (2014) It's not fair... or is it? The role of justice and leadership in explaining work stressor-job performance relationships. Academy of Management Journal, 57(3), pp.675-697. doi: doi.org/10.5465/amj.2011.1110.

Zhao JS, He N and Lovrich N (2002) Predicting five dimensions of police officer stress: Looking more deeply into organizational settings for sources of police stress. Police Quarterly, 5(1), pp.43-62. doi: 10.1177/109861110200500103. 
Table 1. Variable, Means, Standard Deviations and Correlations in Study 1

\begin{tabular}{|c|c|c|c|c|c|c|c|c|c|}
\hline Variables & Mean & s.d. & 1 & 2 & 3 & 4 & 5 & 6 & 7 \\
\hline 1. Gender & .39 & .49 & & & & & & & \\
\hline 2. Age & 2.34 & .99 & $-.16 * *$ & & & & & & \\
\hline 3. Job Roles & .38 & .48 & $.23 * *$ & $.13 * *$ & & & & & \\
\hline 4. Tenure in Policing & 2.77 & 1.09 & $-.19 * *$ & $.55^{* *}$ & $-.27 * *$ & & & & \\
\hline 5. Challenge Stressors & 4.02 & .70 & $-.11 *$ & $-.11 *$ & $-.33 * *$ & $.12 * *$ & & & \\
\hline 6. Hindrance Stressors & 3.04 & .78 & -.07 & $-.12 *$ & $-.35 * *$ & $.12 * *$ & $.48 * *$ & & \\
\hline 7. Exhaustion & 4.22 & 1.12 & .01 & $-.18 * *$ & $-.36 * *$ & .00 & $.40 * *$ & $.58 * *$ & \\
\hline 8. Engagement & 5.62 & 1.07 & $.11 *$ & $.11^{*}$ & $.20 * *$ & -.02 & .09 & $-.28 * *$ & $-.43 * *$ \\
\hline
\end{tabular}

Notes. $\mathrm{N}=469$. s. $d=$ standard deviation. Gender was coded as $0=$ male, $1=$ female; Age was coded as $0=16-24$ years, $1=25-34$ years, $2=35-44$ years, $3=45-54$ years, and $4=55$ years above. Job roles was coded as $0=$ police officers, $1=$ police staff. Tenure in policing was coded as $0=$ less than 1 year, $1=1-5$ years, $2=6-10$ years, $3=11-20$ years, and $4=20$ years and above.

$* p<.05, * * p<.01$. 
Table 2. Regression Analyse Results for Challenge Stressors and Hindrance Stressors in Study1

\begin{tabular}{lcccc}
\hline & \multicolumn{2}{c}{ Exhaustion } & \multicolumn{2}{c}{ Work Engagement } \\
\hline Control variables & Model la & Model $2 a$ & Model 1b & Model $2 b$ \\
Gender & .16 & $.18^{*}$ & $.20^{*}$ & $.24^{*}$ \\
Age & $-.13^{*}$ & -.03 & $.13^{*}$ & $.12^{*}$ \\
Job Roles & $-.85^{* * *}$ & $-.45^{* * *}$ & $.36^{* *}$ & $.31^{* *}$ \\
Tenure in Policing & -.02 & -.10 & -.02 & -.01 \\
Independent variables & & & & $.52^{* * *}$ \\
Challenge Stressors & & $.20^{* *}$ & & $-.51^{* * *}$ \\
Hindrance Stressors & & $.67 * * *$ & & .19 \\
$R^{2}$ & .15 & .40 & .06 &
\end{tabular}

Notes. $\mathrm{N}=469$. Unstandardized regression coefficients are shown. Gender was coded as $0=$ male, $1=$ female; Age was coded as $0=16-24$ years, $1=25-34$ years, $2=35-44$ years, $3=45-54$ years, and $4=55$ years above. Job roles was coded as $0=$ police officers, $1=$ police staff. Tenure in policing was coded as 0 $=$ less than 1 year, $1=1-5$ years, $2=6-10$ years, $3=11-20$ years, and $4=20$ years and above.

$* p<.05, * * p<.01, * * * p<.001$ 
Table 3. Variable, Means, Standard Deviations and Correlations in Study 2

\begin{tabular}{|c|c|c|c|c|c|c|c|c|c|}
\hline Variables & Mean & s.d. & 1 & 2 & 3 & 4 & 5 & 6 & 7 \\
\hline 1. Gender & 1.44 & .50 & & & & & & & \\
\hline 2. Job Roles & .50 & .50 & $.26 * *$ & & & & & & \\
\hline 3. Challenge Stressors T1 & 3.95 & .66 & -.01 & $-.19 * *$ & & & & & \\
\hline 4. Hindrance Stressors T1 & 2.96 & .74 & $-.10 * *$ & $-.22 * *$ & $.43 * *$ & & & & \\
\hline 5. Exhaustion T1 & 4.10 & 1.16 & -.04 & $-.32 * *$ & $.35 * *$ & $.50 * *$ & & & \\
\hline 6. Engagement T1 & 5.67 & .95 & $.08^{*}$ & $.17 * *$ & $.10 * *$ & $-.26 * *$ & $-.44 * *$ & & \\
\hline 7. Exhaustion $\mathrm{T} 2$ & 4.39 & 1.09 & -.03 & $-.27 * *$ & $.28 * *$ & $.39 * *$ & $.66^{* *}$ & $-.30 * *$ & \\
\hline 8. Engagement T2 & 5.69 & .94 & .05 & $.07 *$ & $.13 * *$ & $-.13 * *$ &.$-30 * *$ & $.60 * *$ & $-.40 * *$ \\
\hline
\end{tabular}


Table 4. Regression Analyse Results for Challenge Stressors and Hindrance Stressors in Study 2

\begin{tabular}{lcccc}
\hline & \multicolumn{2}{c}{ Exhaustion T2 } & \multicolumn{2}{c}{ Engagement T2 } \\
\hline Control variables & Model la & Model 2a & Model 1 $b$ & Model $2 b$ \\
Gender & .05 & .05 & .03 & .02 \\
Job Roles & $-.16^{*}$ & $-.14^{*}$ & -.05 & -.03 \\
Exhaustion T1 & $.60^{* * *}$ & $.56^{* * *}$ & -- & -- \\
Engagement T1 & & & $.59 * * *$ & $.58^{* * *}$ \\
Independent variables & & & & $.10^{*}$ \\
Challenge Stressors T1 & & .05 & & -.01 \\
Hindrance Stressor T1 & & $.10^{*}$ & & .36 \\
$R^{2}$ & .44 & .45 & .35 & \\
\hline
\end{tabular}

Notes. $\mathrm{N}=823$. Unstandardized regression coefficients are shown. $\mathrm{T} 1=$ Time $1 . \mathrm{T} 2=$ Time 2,24 months after Time 1 . Gender was coded as $0=$ male, $1=$ female; Job roles was coded as $0=$ police officer, $1=$ police staff.

$* p<.05, * * p<.01, * * * p<.001$ 


\section{Figure 1 Conceptual Model}

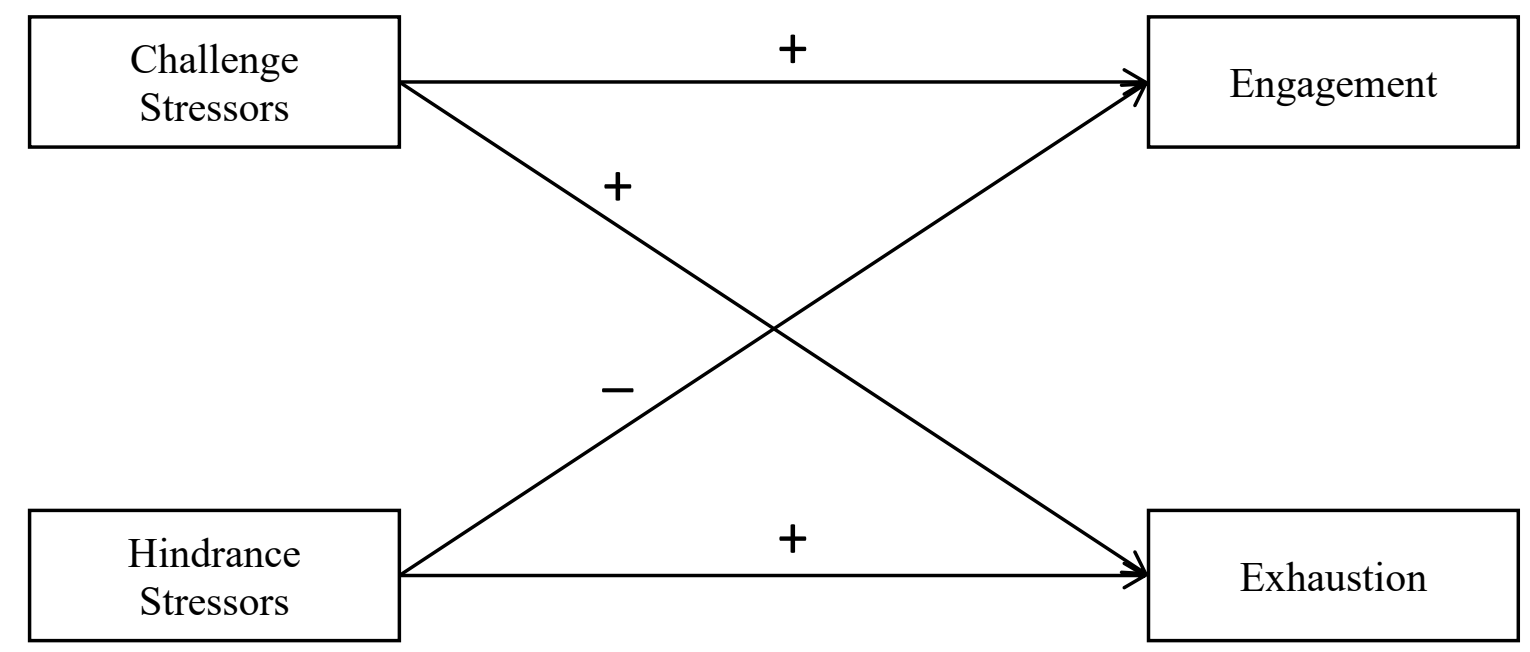

